\title{
Epigenetic effects of metformin: from molecular mechanisms to clinical
}

\section{implications}

\author{
Bridgeman, $\mathrm{SC}^{1}$; Ellison, GC ${ }^{1}$; Melton, $\mathrm{PE}^{1,2}$; Newsholme, ${ }^{1}$; Mamotte, $\mathrm{CDS}^{1}$. \\ 1. School of Pharmacy and Biomedical Sciences, and Curtin Health Innovation \\ Research Institute, Curtin University, Perth, Western Australia \\ 2. Centre for Genetic Origins of Health and Disease, Faculty of Health and Medical \\ Science, the University of Western Australia, Perth, Western Australia
}

Corresponding author: Cyril Mamotte, c.mamotte@curtin.edu.au

Running title: Epigenetic effects of metformin

\begin{abstract}
There is a growing body of evidence that links epigenetic modifications to type 2 diabetes. Researchers have more recently investigated effects of commonly used medications, including those prescribed for diabetes, on epigenetic processes. This work reviews the influence of the widely used antidiabetic drug metformin on epigenomics, microRNA levels and subsequent gene expression and potential clinical implications. Metformin may influence the activity of numerous epigenetic modifying enzymes, mostly via modulating the activation of AMP-activated protein kinase (AMPK). Activated AMPK can phosphorylate numerous substrates, including epigenetic enzymes such as histone acetyltransferases (HATs), class II histone deacetylases (HDACs) and DNA methyltransferases (DNMTs), generally resulting in their inhibition, although HAT1 activity may be increased. Metformin has also been reported to decrease expression of multiple histone methyltransferases, increase the activity of the class III HDAC SIRT1 and to decrease the influence of DNMT inhibitors. There is evidence that these alterations influence the epigenome and gene expression, and may contribute to the antidiabetic properties of metformin and potentially protect against cancer, cardiovascular disease, cognitive decline and aging. The expression levels of numerous microRNAs are also reportedly influenced by metformin treatment and may confer antidiabetic and anticancer
\end{abstract}

This article has been accepted for publication and undergone full peer review but has not been through the copyediting, typesetting, pagination and proofreading process, which may lead to differences between this version and the Version of Record. Please cite this article as doi: 10.1111/dom.13262 
activities. However, as the reported effects of metformin on epigenetic enzymes act to both increase and decrease histone acetylation, histone and DNA methylation, and gene expression, a significant degree of uncertainty exists on the overall effect of metformin on the epigenome, gene expression and subsequent effect on the health of metformin users. 


\section{Introduction}

Epigenetics is a rapidly growing field in medical research. Epigenetic modifications, changes to DNA structure that alter gene expression without altering the base nucleotide code, are crucial in the development of organisms and the differentiation and function of specific cell types. For example, epigenetic modifications permit the expression of the insulin gene in pancreatic $\beta$ cells, while silencing it in other cells. ${ }^{1}$ However, epigenetic changes have also been associated with numerous disorders, including type 2 diabetes (T2D), CVD and cancer. ${ }^{2,3}$ Epigenetic processes can be altered by environmental factors including diet, exercise and exposure to toxins, with the foetal environment playing a particularly important role in influencing epigenetic modifications that impact metabolism in adult life; both maternal nutrient deficiency and maternal obesity have been linked to epigenetic changes and the development of T2D in offspring. ${ }^{4}$ There is growing evidence that pharmaceuticals also alter epigenetic processes, which may contribute to the beneficial and deleterious effects of widely-used medications. ${ }^{5}$

As a result of the morbidities and growing prevalence of T2D, the use of medications designed to lower blood glucose is widespread and growing. The biguanide drug metformin is the most widely prescribed antidiabetic drug and is considered the gold standard for the treatment of T2D. ${ }^{6}$ In 2012, over 60 million prescriptions were filled for metformin in the United States, an increase of $97 \%$ from 2003. ${ }^{7}$ Therefore, any epigenetic effects of metformin may affect the health of a significant number of individuals. Furthermore, as metformin can treat gestational diabetes, this may alter the foetal environment and thus affect the health of offspring. This review explores the epigenetic effects of metformin, including how they may modulate its glucose lowering and off-target activity, including potential protection from cardiovascular disease, cancer, cognitive decline and aging.

\section{Epigenetic modifications}

Epigenetic modifications fall under two main categories: histone modifications and DNA methylation. Although they do not directly interact with DNA, microRNAs are also often included as having epigenetic-like effects as they alter protein expression through the suppression of mRNA translation.

\section{Histone modifications}

DNA is wrapped around histone cores composed of two each of histone proteins $\mathrm{H} 2 \mathrm{~A}, \mathrm{H} 2 \mathrm{~B}, \mathrm{H} 3$ and $\mathrm{H} 4$; this structure is termed a nucleosome and comprises the fundamental unit of chromatin. DNA can be loosely packed and amenable to transcription as in euchromatin, or highly condensed and silenced as in heterochromatin; the state of organisation being determined by post-translational modifications to histone amino-terminal tails, most notably acetylation, phosphorylation and methylation.

This article is protected by copyright. All rights reserved. 
Acetylation of histone lysine residues, particularly of $\mathrm{H} 3$ and $\mathrm{H} 4$, neutralises their positive charge and subsequently promotes an open chromatin structure. ${ }^{8}$ Histone hyperacetylation is thus considered a signature of active transcription. Histone acetylation is highly dynamic and regulated by two opposing families of enzymes, histone acetyltransferases (HATs) and histone deacetylases (HDACs). HATs add acetyl groups to lysine residues using acetyl-CoA as a cofactor. Of the two classes of HATs, Type-A HATs, including the CBP/p300 family, modify multiple sites in histone tails and act as transcriptional co-activators, whereas Type-B HATs, including HAT1, are cytoplasmic and acetylate newly formed histone proteins but not those already complexed to DNA. ${ }^{8}$ HDACs are divided into 4 classes; class I HDACs, including HDAC 1, 2, 3 and 8, are nucleic whereas class II HDACs, including HDAC 4, 5, 6, 7, 9 and 10, move between the nucleus and cytoplasm. ${ }^{9}$ Class III HDACs, also known as sirtuins, include SIRTs 1 to 7 and are associated with longevity and decreased disorders of aging, including T2D. ${ }^{10}$ HDAC11 is the only class IV HDAC, of which little is known. Unlike class I, II and IV HDACs, which are zinc dependent, sirtuins rely on NAD+ for their deacetylating activity.

Similar to acetylation, histone phosphorylation neutralises the positive charge of the histone. ${ }^{8}$ Serine, threonine and tyrosine residues serve as the phosphorylation/dephosphorylation sites for protein kinases and phosphatases respectively, in a process considered important for transcription, and therefore gene expression, as well as DNA repair, mitosis and apoptosis. ${ }^{11}$

Unlike acetylation and phosphorylation, methylation of histone lysine or arginine residues does not alter the charge of the histone and can have varying influences on transcription depending on the specific residue methylated (denoted by the histone protein and the lysine $[\mathrm{K}]$ or arginine $[\mathrm{R}]$ that is methylated) and the degree of methylation (mono-, di- or trimethylation). Histone methylation involves the transfer of methyl groups from S-adenosylmethionine (SAM) to histone residues, catalysed by histone methyltransferases (HMT). Methylation of histone lysines H3K4, H3K36, and H3K79 is generally associated with active transcription, whereas methylation of H3K9, H3K27, and H4K20 is more commonly found on transcriptionally silent genes. ${ }^{12}$ Most HMTs are specific to a certain histone residue, for example enhancer of zeste homolog 2 (EZH2) trimethylates H3K27. Histone methylation is not as dynamic as acetylation and was thought to be a stable event until discovery of the first histone demethylase was reported in $2004 .^{13}$

Numerous other post-translational modifications to histones have been discovered, including ubiquitination, sumoylation, O-GlcNAcylation, and ADP-ribosylation, although it is less clear how these modifications impact gene expression and other processes affected by chromatin configuration.

\section{DNA methylation}

DNA methylation occurs when a methyl group is transferred from SAM to nucleotides by DNA methyltransferases (DNMTs). In vertebrates, it is thought that methylation only occurs to cytosine 
bases in $\mathrm{CpG}$ dinucleotides. ${ }^{14} \mathrm{CpG}$ dinucleotides are rare throughout the genome, accounting for only $1 \%$ of cytosines, but occur at a high frequency in the majority (approximately $70 \%$ ) of gene promoters. ${ }^{15}$ These regions of $\mathrm{CpG}$ clusters are termed $\mathrm{CpG}$ islands. Most cytosines in $\mathrm{CpG}$ islands are unmethylated, with hypermethylation of $\mathrm{CpG}$ islands generally resulting in transcriptional silencing due to decreased transcription factor binding and increased binding of methyl-CpG binding proteins, which may initiate histone modification and subsequent chromatin condensation. ${ }^{14}$

Four DNMTs with DNA methyltransfase activity have been identified, DNMT1, DNMT3a, DNMT3b and DNMT3c, while DNMT3L lacks methyltransferase activity and instead acts as a cofactor to de novo methyltransferases and DNMT2 methylates tRNA. ${ }^{16}$ DNMT3a and DNMT3b are the de novo methyltransferases; they establish methylation in previously unmethylated cytosines, whereas DNMT1 maintains a state of methylation, for example in daughter cells following replication. ${ }^{17}$ The recently described DNMT3c has been reported to silence retrotransposons in the germ cells of male mice. $^{18}$

\section{MicroRNAs}

MiRNAs are short, non-coding RNAs that regulate gene expression through interaction with mRNA as part of the miRNA-induced silencing complex (miRISC). Due to their small size (approximately 21-24 nucleotides) and ability to bind even when complementarity is not perfect, each miRNA can target hundreds of mRNAs. Subsequently, translation is repressed by the blocking of translation initiation factors and the degradation of target mRNAs through the recruitment of deadenylating and decapping enzymes, followed by nucleases. ${ }^{19}$

\section{Metformin}

Metformin reduces hyperglycaemia by decreasing hepatic gluconeogenesis and increasing insulin sensitivity. ${ }^{20}$ It is also used in the treatment of polycystic ovary syndrome (PCOS) to induce ovulation and regulate menstruation, ${ }^{21}$ and may have additional benefits with meta-analyses reporting a reduced risk of cardiovascular mortality ${ }^{22}$ and cancer $^{23}$ in individuals on metformin therapy. Metformin may also be neuroprotective, with placebo-controlled randomized clinical trials reporting metformin improves cognitive function in the cognitively impaired, such as those with Alzheimer's disease. ${ }^{24,25}$ Metformin was also suggested as an antiaging drug as early as the $1970 \mathrm{~s},{ }^{26}$ and is currently being investigated in randomised controlled trials such as the Targeting Aging with Metformin (TAME) trial. ${ }^{27}$ Metformin is generally well tolerated with gastrointestinal disturbances, particularly diarrhoea, being the most common side effect; less frequently liver damage and lactic acidosis have also been reported. ${ }^{28}$ While the exact mechanisms of action are not completely understood, metformin's ability 
to promote the phosphorylation and hence the activation of AMP activated protein kinase (AMPK) is considered to be central to its mode of action and to result in the inhibition of gluconeogenic genes. ${ }^{20}$ Activation of AMPK, considered a major regulator of cellular metabolism, also impacts numerous pathways, not only those involved in glucose metabolism but also lipid metabolism, mitochondrial biogenesis, autophagy, cell growth and circadian rhythm. ${ }^{29}$

There is emerging evidence that metformin-induced modulation of AMPK activity influences epigenetic processes. Given metformin's widespread use, including in gestational diabetes and PCOS, this may be of concern. Studies exploring the effect of maternal metformin on offspring have been limited to short-term studies, and therefore the outcome regarding long-term metabolic effects is not yet known. Follow-up of the Metformin in Gestational diabetes (MiG) trial found offspring exposed prenatally to metformin had a preferable pattern of fat distribution at 2 years,${ }^{30}$ while a Finnish study found children exposed to metformin and supplemental insulin in utero were heavier at 18 months than children exposed to insulin alone. ${ }^{31}$ Similarly, a trial of metformin use for PCOS during pregnancy found infants whose mothers took metformin were heavier at one year. ${ }^{32}$ Animal studies report mixed results; with one study by Salomaki et al. ${ }^{33}$ reporting increased weight gain and impaired glucose tolerance in mice on a high fat diet (HFD) exposed to metformin in utero, and a later study by the same group finding prenatal metformin exposure protected mice from HFD-induced weight gain and impaired glucose tolerance. ${ }^{34}$

\section{Metformin and epigenetic aging}

While the clinical effects of metformin as a pharmacological intervention to promote healthy aging and longevity are currently being investigated in clinical trials, ${ }^{27,35}$ few studies have attempted to do so in the context of epigenetics. Epigenetic markers of aging accumulate with hyperglycaemia, hyperinsulinaemia and metabolic syndrome, ${ }^{36,37}$ and correction of these metabolic abnormalities with metformin may ameliorate epigenetic aging. Metformin may also influence epigenetic aging through interaction with epigenetic modifying enzymes such as SIRT1, the HDAC associated with longevity. The clinical effects of metformin are similar to those of calorie restriction, an intervention known to prolong life, ${ }^{37}$ and there is a growing body of evidence that SIRT1 plays an important role in mediating the anti-aging effects of calorie restriction, including antidiabetic actions. ${ }^{10}$ In a randomised controlled trial, two months of metformin altered levels of several effectors associated with longevity, including increased SIRT1 expression in peripheral blood mononuclear cells. ${ }^{35}$

In a recent observational study by Quach, et al. ${ }^{36}$, the degree of DNA methylation in peripheral blood (the 'epigenetic clock') was used to assess the effect of a variety of lifestyle factors on the rate of epigenetic aging, known as epigenetic age acceleration. Metformin did not significantly alter extrinsic

This article is protected by copyright. All rights reserved. 
or intrinsic epigenetic age acceleration, although several other dietary and behavioural factors did. However, while epigenetic age acceleration has been found to correlate closely with expected longevity, it has not been validated as a means of assessing specific pharmacological effects, but rather is considered to reflect the 'cumulative effect of an epigenetic maintenance system. ${ }^{38}$ Furthermore, as pointed out by the authors, lack of power and the observational design of this study may mask a real effect, and randomised controlled trials may provide a more convincing result.

\section{Metformin and histone modifications}

Metformin-induced activation of AMPK has been reported to impact histone modifications via multiple mechanisms, including modifications that both increase and decrease gene expression (Figure 1). This includes phosphorylation of HATs, increased SIRT1 activity, inhibition of class II HDACs, and potentially phosphorylation of histone residues. There is also evidence that metformin may influence HAT expression through AMPK-independent mechanisms, and inhibit HMT expression and histone ubiquitination.

\section{HATs}

The effect of AMPK activation on HATs varies, increasing the activity of some HATs and decreasing others, and thus metformin may likewise have varying effects. For example, Marin, et al. ${ }^{39}$ reported, using a mouse embryonic fibroblast model, that via AMPK activation, metformin induced HAT1 phosphorylation, increasing its activity. Conversely, in multiple other studies, the phosphorylation of the HATs p300 and CREB-binding protein (CBP) by AMPK reduced their activity. ${ }^{40-43}$

P300 and CBP are important transcriptional co-activators of multiple genes involved in inflammation and gluconeogenesis. He, et al. ${ }^{40}$ demonstrated that metformin induced phosphorylation of CBP at Ser436. This prevented the formation of the CREB-CBP-TORC2 transcription complex and decreased CBP occupancy at the promoter regions of gluconeogenic genes including peroxisome proliferatoractivated receptor gamma coactivator 1-alpha $(P G C 1 \alpha)$ and phosphoenolpyruvate carboxykinase 1 (Pck1). Metformin significantly decreased blood glucose levels in wild-type mice but did not in mice with mutant CBP (S436A), suggesting this mechanism may play a key role in the antidiabetic activity of metformin.

Similarly, metformin-induced AMPK activation results in p300 phosphorylation at Ser89, decreasing its enzymatic activity. ${ }^{42}$ AMPK-mediated p300 phosphorylation was found to reduce its interaction with nuclear receptors including PPAR $\gamma,{ }^{43}$ and consequently may reduce the transcription of PPAR $\gamma$ target genes, including genes involved in lipid and glucose metabolism. As PPAR $\gamma$ is considered 
beneficial in T2D, with PPAR $\gamma$ agonists such as thiazolidinediones prescribed as insulin-sensitising agents, it is unclear how this influences the effects of metformin on glucose metabolism.

AMPK may also promote the proteasomal degradation of $\mathrm{p} 300$; Lim, et al. ${ }^{41}$ demonstrated that metformin and AICAR, an unrelated AMPK agonist, reduced p300 protein, but not mRNA, levels in hepatic stellate cells, with proteasome inhibition restoring protein levels.

Metformin also increased mRNA and protein levels of Gen5, a type A HAT, in diabetic mice and in a hepatocyte cell line. ${ }^{44}$ However, this was not influenced by an AMPK inhibitor, suggesting metformin alters Gcn5 expression through an unknown, AMPK-independent mechanism.

\section{HDACS}

As with HATs, the effect of metformin-induced AMPK activation has differing effects on the activity of different HDAC classes, decreasing the deacetylation of class II HDACs while increasing the activity of the class III HDAC SIRT1. Khan et al. ${ }^{45}$ demonstrated both an inhibitory effect on HDAC activity in rat liver and a consequent increase in global $\mathrm{H} 3$ acetylation following metformin treatment. HDAC inhibition with metformin has also been demonstrated in cancer cells. ${ }^{46}$ This may be a result of HDAC phosphorylation; it has been demonstrated that AMPK phosphorylates HDAC4, 5 and 7 at Ser259 and Ser $498,{ }^{47}$ and that such phosphorylation of HDAC5 results in its export from the nucleus and subsequently de-repression of target genes. ${ }^{48}$ This may contribute to the antidiabetic activity of metformin; a previous study reported that AMPK activation decreased HDAC5 association with the glucose transporter type 4 (GLUT4) gene, resulting in increased GLUT4 expression in human primary myotubes, suggesting a direct mechanism by which metformin could ameliorate insulin resistance in muscle cells. ${ }^{49}$

As opposed to the inhibitory effect on class II HDACs, AMPK activation increases SIRT1 activity. ${ }^{44}$ This is thought to be a result of NAD+ generation, as both metformin and overexpression of a constitutively active AMPK were reported to increase the NAD+/NADH ratio in myotubes. ${ }^{50}$ Metformin may also increase SIRT1 gene expression; in a randomised controlled trial, two months of metformin treatment increased SIRT1 mRNA and protein levels in peripheral blood mononuclear cells, although no increase in SIRT1 deacetylase activity was detected. ${ }^{35}$ Effects may differ in cancer cells, where metformin has been shown to reduce SIRT1 protein expression. ${ }^{51}$ This is mediated through effects on miR-34a, as discussed in a later section.

In animal models, increased SIRT1 activity with metformin has been associated with inhibition of gluconeogenesis in the liver, implicating SIRT1 with the antidiabetic actions of metformin. Caton, et al. ${ }^{44}$ found metformin treatment increased the NAD+/NADH ratio and SIRT1 activity in diabetic mice while decreasing plasma insulin and glucose as well as expression of the gluconeogenic enzyme Pckl. 
Co-incubation of hepatocytes with inhibitors of either AMPK or SIRT1 reduced the antidiabetic effects of metformin, specifically increasing cellular glucose levels and Pckl expression and activity.

There is also evidence that metformin may reduce cellular aging and improve cardiovascular health through SIRT1, in particular by protecting vascular endothelial cells from cellular stress. In human umbilical vascular endothelial cells, treatment with metformin increased SIRT1 expression and activity and reduced signs of cellular aging and production of reactive oxygen species. ${ }^{52}$ These effects were prevented when AMPK was silenced by siRNA. Similarly, Arunachalam, et al. ${ }^{53}$ found metformin increased SIRT1 expression and conferred protective effects in cultured mouse microvascular endothelial cells exposed to high glucose, including increased levels of the antiapoptotic Bcl-2 protein and reduced cellular senescence. Silencing SIRT1 prevented these protective effects.

SIRT1 has also been associated with neuroprotection in cell-based and animal models of aging and T2D and controlled clinical trials with resveratrol, a SIRT1 activator, have shown improved cognitive function. ${ }^{54}$ In mice on a high fat diet, metformin increased hippocampal SIRT1 gene expression. ${ }^{55}$ Although this study did not find significant changes in memory or learning with metformin treatment, this mechanism could potentially contribute to the reported neuroprotective effects of metformin.

\section{Histone methylation}

There is evidence that metformin can influence the methylation of numerous histone lysine residues. While both increases and decreases of lysine methylation have been reported, all these modifications are consistent with an increase in gene expression due to the previously mentioned fact that methylation of lysine residues can either activate (H3K4, H3K36) or repress (H3K9, H3K27) transcription. In particular, as these studies were conducted using cancer cells to investigate the potential anticancer activity of metformin, changes in histone methylation due to metformin treatment may lead to increased expression of tumour suppressor genes. For example, Banerjee, et al. ${ }^{46}$ reported that metformin treatment decreased $\mathrm{H} 3 \mathrm{~K} 9$ and $\mathrm{H} 3 \mathrm{~K} 27$ methylation, as well as increased $\mathrm{H} 3 \mathrm{~K} 4$ methylation in breast cancer cells, both globally and specifically at the promoter of the tumour suppressor gene E-cadherin. These modifications may be a result of inhibition of HMTs; reductions of mRNA and protein expression of SUV39H1 ${ }^{56}$ and MMSET,${ }^{57} \mathrm{HMTs}$ that influence the methylation of $\mathrm{H} 3 \mathrm{~K} 9$ and $\mathrm{H} 3 \mathrm{~K} 27$ respectively, have been reported in metformin treated prostate cancer cells. The mechanism by which metformin may inhibit HMTs is unknown as these studies did not examine whether AMPK is directly responsible for the reported effects.

Conversely, one study has reported that AMPK can increase histone demethylase activity, although this study did not use metformin treatment. Tanaka, et al. ${ }^{58}$ demonstrated that AMPK can reduce H3K36 methylation through lysine-specific demethylase 2A (KDM2A) activity. AMPK activation by 
AICAR reduced H3K36 dimethylation at the rDNA promoter with subsequent reduced transcription of rDNA in breast cancer cells. KDM2A knockdown prevented these effects.

\section{Other histone modifications}

The direct influence of metformin on histone phosphorylation has not been studied, however Bungard, et al. ${ }^{59}$ found that AMPK activation by a related biguanide, phenformin, resulted in the phosphorylation of H2B at Ser36 in mouse embryonic fibroblasts. Abrogation of phosphorylation by Ser36>Ala36 substitution reduced the transcription of AMPK target genes. Furthermore, a study of Sertoli cells found AMPK knockout resulted in a reduction of phosphorylated $\mathrm{H} 2 \mathrm{~B} .{ }^{60}$

AMPK activation has also been associated with a decrease in ubiquitination and O-GlcNAcylation of residues on $\mathrm{H} 2 \mathrm{~B}$. $\mathrm{Xu}$, et al. ${ }^{61}$ reported that activation of AMPK by AICAR in mouse embryonic fibroblasts resulted in the phosphorylation of O-linked $\beta$-N-acetylglucosamine (O-GlcNAc) transferase, the enzyme responsible for histone O-GlcNAcylation, i.e. the addition of O-linked Nacetylglucosamine (O-GlcNAc). This decreased the affinity of the enzyme for chromatin and thus reduced O-GlcNAcylation of $\mathrm{H} 2 \mathrm{~B}$ at Ser112, both globally and at the region of several target genes associated with repression of these genes. As O-GlcNAcylation is thought to promote histone ubiquitination, they also found reduced ubiquitination at H2BK120. Although this study used a different AMPK activator, metformin has been proven to decrease H2BK120 ubiquitination in breast cancer cells. ${ }^{62}$ These studies both associated ubiquitination and O-GlcNAcylation with increased gene expression, although both modifications have also been associated with gene silencing and linked to a variety of other histone modifications that may alter chromatin structure. ${ }^{61,63}$

\section{Metformin and DNA methylation}

Reported effects of metformin on DNA methylation include both hypo and hypermethylation at the promoters of different genes. ${ }^{46,64-66}$ Furthermore, it has been reported that AMPK directly inhibits DNA methyltransferase activity, while metformin may indirectly reduce the activity of endogenous DNMT inhibitors. As a result, the overall effect of metformin on DNA methylation and subsequent gene expression is unclear.

Reduced DNA methylation with metformin treatment has been reported at the insulin gene promoter in a $\beta$ cell line cultured using high glucose concentrations ${ }^{65}$ and at the promoter of the tumour suppressor gene E-cadherin in both cancer cell lines and in white blood cells from diabetics, ${ }^{46}$ leading to increased expression of the respective genes. These results thus implicate DNA demethylation in the antidiabetic and potential anti-cancer actions of metformin. Additionally, reduced methylation of transporter genes $S L C 22 A 1, S L C 22 A 3$, and $S L C 47 A 1$, all involved in hepatic transport of metformin, 
was reported in the livers of diabetics receiving metformin compared to those not receiving any antidiabetic medication. ${ }^{66}$ Interestingly, these changes were not apparent in patients receiving metformin plus insulin. These changes in methylation may be a result of reduced DNMT activity; activation of AMPK by metformin has been reported to phosphorylate DNMT1 at Ser730 and consequently inhibit its methyltransferase activity. ${ }^{39}$ This was associated with a decrease in promoter methylation of six target genes in wild type mouse embryonic fibroblasts, but not in AMPK knockout cells or cells with DNMT1 Ser730>Ala730 substitution. Furthermore, metformin treatment reduced DNMT1 protein expression in several human lung cancer cell lines. ${ }^{67}$

Conversely, several studies indicate that metformin may induce DNA hypermethylation via increased activity of S-adenosylhomocysteine hydrolase (SAHH). SAHH hydrolyses and thus inactivates S-adenosylhomocysteine (SAH), a feedback inhibitor of DNMT activity. Recently, it was reported that metformin decreased SAH levels in non-malignant breast epithelial cells and increased global DNA methylation in a variety of malignant and non-malignant cells. ${ }^{68}$ AMPK knockout cells were resistant to these changes. Zhong, et al. ${ }^{64}$ demonstrated that metformin increases SAHH activity and alters the methylation of numerous gene promoters in endometrial cancer cells. A SAHH inhibitor blocked the metformin-induced hypermethylation of five genes. Interestingly, the metformin-induced increase in SAHH activity may itself be due to DNA hypermethylation. The long noncoding RNA H19 has been demonstrated to bind and thus inhibit SAHH, ${ }^{64}$ and Yan, et al. ${ }^{69}$ reported increased methylation of the $H 19$ promoter and subsequent reduced H19 expression with metformin treatment in endometrial and ovarian cancer cells.

\section{Metformin and microRNAs}

Metformin has been reported to alter the expression of numerous miRNAs. Alterations in miRNA expression by metformin may be partially explained by an increase in DICER, one of the key enzymes in miRNA processing. Increases in DICER protein levels have been reported in metformin treated diabetic humans and mice, ${ }^{70}$ and in cancer cells. ${ }^{71}$ This increase was also reported in cells treated with AICAR, suggesting AMPK activation as a mechanism. ${ }^{71}$

\section{Metformin-altered miRNAs in cancer}

The potential anti-cancer properties of metformin have been linked to the regulation of numerous miRNAs (see Table 1). MiRNAs that may be important in the potential anti-cancer activity of metformin include upregulation of the let-7 family, miR-26a and miR-34a and downregulation of miR-181a, miR-221 and miR-222. Let-7 miRNAs are downregulated in many cancers and target mRNA of oncogenes including Ras and c-Myc, ${ }^{72}$ while also inhibiting expression of the SAHH 
inhibitor H19 and thus impacting DNA methylation (see previous section). ${ }^{64}$ MiR-26a is also downregulated in many tumours and has been found to inhibit proliferation and induce apoptosis through the suppression of a number of oncogenes including EZH2, Oct4 and Notch-1. ${ }^{73}$ MiR-34a is a transcriptional target of the tumour suppressor p53 and inhibits a number of oncogenes including cMyc, c-MET and Notch, in addition to the anti-apoptotic Bcl-2 and the HDAC SIRT1. ${ }^{74}$ The oncogenic miR-181a induces and maintains stem cell phenotypes in cancer cells by targeting transcription factors involved in cell differentiation, ${ }^{75}$ while miR-221 and miR-222 promote cancer proliferation through the suppression of cell cycle inhibitors such as p27 and p57..$^{76,77}$

\section{Metformin-altered miRNAs in diabetes and diabetes complications}

MiRNAs may contribute to the beneficial effects of metformin in diabetics, particularly in reducing the risk of diabetes-associated conditions such as cardiovascular disease, liver disease and diabetic nephropathy.

In one study, Santovito, et al. ${ }^{78}$ reported 25 miRNAs with altered expression in diabetics, including downregulation of let-7 family miRNAs. Twelve months of metformin treatment combined with lifestyle changes significantly increased the expression of let-7a and let-7f. Although overexpression of let-7 has been associated with reduced insulin secretion and insulin sensitivity in mice, ${ }^{79}$ a recent study by Brennan, et al. ${ }^{80}$ suggests let-7 miRNAs may protect against inflammation in diabetic atherosclerotic plaques. Additionally, the internal mammary arteries of diabetics on metformin were found to have lower levels of miR-221 and miR-222 compared to diabetics not on metformin. ${ }^{81}$ Inhibition and transfection of these miRNAs respectively reduced and increased the proliferation of isolated vascular smooth muscle cells, leading the authors to suggest that this mechanism may protect against intimal thickening in diabetes. Metformin may also improve impaired angiogenesis in diabetic vascular disease through miR-34a-mediated regulation of SIRT1 expression. Arunachalam, et al. ${ }^{82}$ found metformin treatment lowered miR-34a expression, increased SIRT1 expression, increased expression of vascular growth factor Ang1 and subsequently increased tube formation in mouse microvascular endothelial cells. This downregulation of miR-34a is contradictory to the results found by multiple experiments in cancer cells and indicates metformin may have differing effects on miRNA expression in cancer cells compared to non-malignant cells.

Downregulation of miR-34a has also been found in livers of metformin treated mice. In a mouse model of liver disease, metformin protected mice from liver fibrosis, inflammation and steatosis and resulted in the downregulation of miR-34a, as well as miR-376a, miR-127, miR-300 and miR-342-3p, and the upregulation of miR-122, miR-194, miR-101b, and miR-705. ${ }^{83}$ MiR-122 is the prominent miRNA in the liver and mice lacking the miR-122 gene develop liver disease and hepatocellular carcinoma, ${ }^{84}$ while increased expression of miR-127 was found to inhibit the proliferation of rat 
hepatocytes and thus may impede regeneration following injury. ${ }^{85} \mathrm{Meng}$, et al. ${ }^{86}$ found metformin treatment decreased levels of miR-291b-3p in the livers of mice on a high fat diet, with levels of this miRNA correlating with lipid accumulation. Overexpression of miR-291b-3p increased hepatic lipid accumulation in mice fed a normal diet, as well as AST and ALT levels, common biomarkers of liver damage. Interestingly, miR-291b-3p was shown to target AMPK $\alpha 1$, the catalytic subunit of AMPK, leading the authors to suggest that miR-291b-3p suppression contributes to the increase of AMPK activity by metformin, and thus may mediate numerous downstream effects.

Low expression of miR-192 has been associated with the progression of diabetic nephropathy and in one study circulating miR-192 levels inversely correlated with markers of impaired renal function (plasma urea and creatinine) in healthy subjects. ${ }^{87}$ In this study, three months of metformin treatment increased plasma miR-192 concentration in diabetics by nearly $50 \%$, although it did not investigate if this resulted in a mitigation of nephropathy.

\section{Limitations of studies}

The majority of studies reporting epigenetic effects of metformin have been conducted using mouse models or cell culture, with a few exceptions using human metformin users (increased SIRT1 expression, ${ }^{35}$ DNA hypomethylation of certain genes ${ }^{46,66}$ and changes in miRNA expression). ${ }^{78,87}$ There are major limitations to these approaches due to differences in physiology between mice and humans and between transformed cell lines in vitro and human tissue in vivo. Furthermore, many studies used suprapharmacological concentrations of metformin in the millimolar concentration range, well above the $40-70 \mu \mathrm{M}$ and 1-40 $\mu \mathrm{M}$ plasma concentrations reported in the portal vein and systemic circulation respectively following therapeutic doses. ${ }^{88}$

This may account for some of the disparate results of the studies. For example, studies reporting DNA hypomethylation with metformin were conducted on diabetics taking therapeutic doses of metformin, ${ }^{46,66}$ or used micromolar doses of $500 \mu \mathrm{M}^{65}$ or $20 \mu \mathrm{M} .{ }^{67}$ Conversely, studies associating metformin with DNA hypermethylation used suprapharmacological concentrations between 1 and 10

$\mathrm{mM}{ }^{64,68-69}$ For a summary of the published studies, including the metformin dose and the model used, see Supplementary Table 1.

Additionally, the reported studies have largely investigated epigenetics in the context of potential beneficial effects of metformin, namely diabetes, cancer, atherosclerosis, cognitive function and aging, and have not investigated if these epigenetic modifications could have detrimental side effects. Finally, it is yet to be reported if metformin use during pregnancy, in conditions such as gestational diabetes or PCOS, may imprint epigenetic signatures onto the offspring that may program long-term metabolic changes.

\section{Conclusion}

This article is protected by copyright. All rights reserved. 
Epigenetics is a rapidly growing field that has been linked with numerous disorders, including T2D. The widely used antidiabetic drug metformin can reportedly modulate numerous epigenetic processes that may contribute to its primary hypoglycaemic action, but may also result in off-target effects, both beneficial and potentially deleterious. Metformin can alter the activity of many different epigenetic modifying enzymes, primarily through the phosphorylating actions of AMPK. However, these include modifications that act to both increase and decrease gene expression. Furthermore, the literature suggests that metformin has opposing effects within the major groups of epigenetic modifying enzymes. Generally, it decreases the activity of most classes of HATs, HDACs and DNMTs through AMPK-mediated phosphorylation, and at the same time reportedly increases HAT1 and SIRT1 activity, and decreases the influence of DNMT inhibitors. This, together with the previously mentioned limitations of published studies, means it is difficult to make generalisations regarding the effects of metformin on the epigenome, subsequent gene expression and what impact this may have on the health of the millions of metformin users worldwide. 


\section{References}

1. Kuroda A, Rauch TA, Todorov I, et al. Insulin gene expression is regulated by DNA methylation. PLoS One 2009;4(9):e6953.

2. Burgio E, Lopomo A, Migliore L. Obesity and diabetes: from genetics to epigenetics. Mol Biol Rep 2015;42(4):799-818.

3. Kanwal R, Gupta K, Gupta S. Cancer epigenetics: an introduction. Methods Mol Biol 2015;1238:325.

4. Lillycrop KA. Effect of maternal diet on the epigenome: implications for human metabolic disease. Proc Nutr Soc 2011;70(1):64-72.

5. Csoka AB, Szyf M. Epigenetic side-effects of common pharmaceuticals: A potential new field in medicine and pharmacology. Med Hypotheses 2009;73(5):770-780.

6. Sharma M, Nazareth I, Petersen I. Trends in incidence, prevalence and prescribing in type 2 diabetes mellitus between 2000 and 2013 in primary care: a retrospective cohort study. BMJ Open 2016;6(1):e010210.

7. Hampp C, Borders-Hemphill V, Moeny DG, Wysowski DK. Use of Antidiabetic Drugs in the U.S., 2003-2012. Diabetes Care 2014;37(5):1367-1374.

8. Bannister AJ, Kouzarides T. Regulation of chromatin by histone modifications. Cell Res 2011;21(3):381-395.

9. Sharma S, Taliyan R. Histone deacetylase inhibitors: future therapeutics for insulin resistance and type 2 diabetes. Pharmacol Res 2016;113(A):320-326.

10. Lavu S, Boss O, Elliott PJ, Lambert PD. Sirtuins: novel therapeutic targets to treat age-associated diseases. Nat Rev Drug Discov 2008;7(10):841-853.

11. Rossetto D, Avvakumov N, Côté J. Histone phosphorylation: a chromatin modification involved in diverse nuclear events. Epigenetics 2012;7(10):1098-1108.

12. Lara E, Calvanese V, Fernandez AF, Fraga MF. Techniques to study DNA methylation and histone modification. In: Roach HI, Bronner F, Oreffo ROC, eds. Epigenetic Aspects of Chronic Diseases. London: Springer London;2011:21-39.

13. Shi Y, Lan F, Matson C, et al. Histone demethylation mediated by the nuclear amine oxidase homolog LSD1. Cell 2004;119(7):941-953.

14. Clouaire T, Stancheva I. Methyl-CpG binding proteins: specialized transcriptional repressors or structural components of chromatin? Cell Mol Life Sci 2008;65(10):1509-1522.

This article is protected by copyright. All rights reserved. 
15. Babenko VN, Chadaeva IV, Orlov YL. Genomic landscape of CpG rich elements in human. BMC Evolutionary Biology 2017;17(Suppl 1):19.

16. Jeltsch A, Ehrenhofer-Murray A, Jurkowski TP, et al. Mechanism and biological role of Dnmt2 in nucleic acid methylation. RNA Biol 2017;14(9):1108-1123.

17. Jin B, Robertson KD. DNA methyltransferases, DNA damage repair, and cancer. Adv Exp Med Bio 2013;754:3-29.

18. Barau J, Teissandier A, Zamudio N, et al. The DNA methyltransferase DNMT3C protects male germ cells from transposon activity. Science 2016;354(6314):909-912.

19. Jonas S, Izaurralde E. Towards a molecular understanding of microRNA-mediated gene silencing. Nat Rev Genet 2015;16(7):421-433.

20. An H, He L. Current understanding of metformin effect on the control of hyperglycemia in diabetes. J Endocrinol 2016;228(3):R97-106.

21. Johnson NP. Metformin use in women with polycystic ovary syndrome. Ann Transl Med 2014;2(6):56.

22. Lamanna C, Monami M, Marchionni N, Mannucci. Effect of metformin on cardiovascular events and mortality: a meta-analysis of randomized clinical trials. Diabetes Obes Metab 2011;13(3):221228.

23. Gandini S, Puntoni M, Heckman-Stoddard BM, et al. Metformin and cancer risk and mortality: a systematic review and meta-analysis taking into account biases and confounders. Cancer Prev Res 2014;7(9):867-885.

24. Koenig AM, Mechanic-Hamilton D, Xie SX, et al. Effects of the insulin sensitizer metformin in Alzheimer disease: pilot data from a randomized placebo-controlled crossover study. Alzheimer Dis Assoc Disord 2017;31(2):107-113.

25. Luchsinger JA, Perez T, Chang H, et al. Metformin in amnestic mild cognitive impairment: results of a pilot randomized placebo controlled clinical trial. J Alzheimers Dis 2016;51(2):501-514.

26. Dilman VM. Age-associated elevation of hypothalamic, threshold to feedback control, and its role in development, ageine, and disease. Lancet 1971;1(7711):1211-1219.

27. Barzilai N, Crandall JP, Kritchevsky SB, Espeland MA. Metformin as a tool to target aging. Cell Metab 2016;23(6):1060-5.

28. Okayasu S, Kitaichi K, Hori A, et al. The evaluation of risk factors associated with adverse drug reactions by metformin in type 2 diabetes mellitus. Biol Pharm Bull 2012;35(6):933-937.

This article is protected by copyright. All rights reserved. 
29. Hardie DG, Ross FA, Hawley SA. AMPK: a nutrient and energy sensor that maintains energy homeostasis. Nat Rev Mol Cell Biol 2012;13(4):251-262.

30. Rowan JA, Rush EC, Obolonkin V, Battin M, Wouldes T, Hague WM. Metformin in gestational diabetes: the offspring follow-up (MiG TOFU): body composition at 2 years of age. Diabetes Care 2011;34(10):2279-2284.

31. Ijas H, Vaarasmaki M, Saarela T, Keravuo R, Raudaskoski. A follow-up of a randomised study of metformin and insulin in gestational diabetes mellitus: growth and development of the children at the age of 18 months. BJOG 2015;122(7):994-1000.

32. Carlsen SM, Martinussen MP, Vanky E. Metformin's effect on first-year weight gain: a follow-up study. Pediatrics 2012;130(5):e1222-1226.

33. Salomaki H, Vahatalo LH, Laurila K, et al. Prenatal metformin exposure in mice programs the metabolic phenotype of the offspring during a high fat diet at adulthood. PLoS One 2013;8(2):e56594.

34. Salomaki H, Heinaniemi M, Vahatalo LH, et al. Prenatal metformin exposure in a maternal high fat diet mouse model alters the transcriptome and modifies the metabolic responses of the offspring. PLoS One 2014;9(12):e115778.

35. de Kreutzenberg SV, Ceolotto G, Cattelan A, et al. Metformin improves putative longevity effectors in peripheral mononuclear cells from subjects with prediabetes. A randomized controlled trial. Nutr Metab Cardiovasc Dis 2015;25(7):686-693.

36. Quach A, Levine ME, Tanaka T, et al. Epigenetic clock analysis of diet, exercise, education, and lifestyle factors. Aging (Albany NY) 2017;9(2):419-437.

37. Anisimov VN. Metformin: do we finally have an anti-aging drug? Cell Cycle 2013;12(22):34833489 .

38. Horvath S. DNA methylation age of human tissues and cell types. Genome Biol 2013;14(10):R115.

39. Marin TL, Gongol B, Zhang F, et al. AMPK promotes mitochondrial biogenesis and function by phosphorylating the epigenetic factors DNMT1, RBBP7, and HAT1. Sci Signal 2017;10(464):eaaf7478

40. He L, Sabet A, Djedjos S, et al. Metformin and insulin suppress hepatic gluconeogenesis by inhibiting cAMP signaling through phosphorylation of CREB binding protein (CBP). Cell 2009;137(4):635-646.

41. Lim JY, Oh MA, Kim WH, Sohn HY, Park SI. AMP-activated protein kinase inhibits TGF- $\beta$ induced fibrogenic responses of hepatic stellate cells by targeting transcriptional coactivator $\mathrm{p} 300$. J Cell Physiol 2012;227(3):1081-1089.

This article is protected by copyright. All rights reserved. 
42. Zhang Y, Qiu J, Wang X, Zhang Y, Xia M. AMP-activated protein kinase suppresses endothelial cell inflammation through phosphorylation of transcriptional coactivator p300. Arterioscler Thromb Vasc Biol 2011;31(12):2897-2908.

43. Yang W, Hong YH, Shen XQ, Frankowski C, Camp HS, Leff T. Regulation of transcription by AMP-activated protein kinase: phosphorylation of p300 blocks its interaction with nuclear receptor. $\mathrm{J}$ Biol Chem 2001;276(42):38341-38344.

44. Caton PW, Nayuni NK, Kieswich J, Khan NQ, Yagood MM, Corder R. Metformin suppresses hepatic gluconeogenesis through induction of SIRT1 and GCN5. J Endocrinol 2010;205(1):97-106.

45. Khan S, Jena G. Sodium butyrate reduces insulin-resistance, fat accumulation and dyslipidemia in type-2 diabetic rat: a comparative study with metformin. Chem Biol Interact 2016;254:124-134.

46. Banerjee P, Surendran H, Chowdhury DR, Prabhakar K, Pal R. Metformin mediated reversal of epithelial to mesenchymal transition is triggered by epigenetic changes in E-cadherin promoter. J Mol Med (Berl) 2016;94(12):1397-1409.

47. Mihaylova Maria M, Vasquez Debbie S, Ravnskjaer K, et al. Class IIa histone deacetylases are hormone-activated regulators of FOXO and mammalian glucose homeostasis. Cell 2011;145(4):607621.

48. Zhao JX, Yue WF, Zhu MJ, Du M. AMP-activated protein kinase regulates $\beta$-catenin transcription via histone deacetylase 5. J Biol Chem 2011;286(18):16426-16434.

49. McGee SL, van Denderen BJW, Howlett KF, et al. AMP-activated protein kinase regulates GLUT4 transcription by phosphorylating histone deacetylase 5. Diabetes 2008;57(4):860-867.

50. Cantó C, Gerhart-Hines Z, Feige JN, et al. AMPK regulates energy expenditure by modulating NAD + metabolism and SIRT1 activity. Nature 2009;458(7241):1056-1060.

51. Do MT, Kim HG, Choi JH, Jeong HG. Metformin induces microRNA-34a to downregulate the Sirt1/Pgc-1 $\alpha / \mathrm{Nrf} 2$ pathway, leading to increased susceptibility of wild-type p53 cancer cells to oxidative stress and therapeutic agents. Free Radic Biol Med 2014;74:21-34.

52. Zhang E, Guo Q, Gao H, Xu R, Teng S, Wu Y. Metformin and resveratrol inhibited high glucoseinduced metabolic memory of endothelial senescence through SIRT1/p300/p53/p21 pathway. PLoS One 2015;10(12):e0143814.

53. Arunachalam G, Samuel SM, Marei I, Ding H, Triggle CR. Metformin modulates hyperglycaemia-induced endothelial senescence and apoptosis through SIRT1. Br J Pharmacol 2014;171(2):523-535.

54. Cao Y, Yan Z, Zhou T, Wang G. SIRT1 regulates cognitive performance and ability of learning and memory in diabetic and nondiabetic models. J Diabetes Res 2017;2017:Article ID 7121827.

This article is protected by copyright. All rights reserved. 
55. Lennox R, Porter DW, Flatt PR, Holscher C, Irwin N, Gault VA. Comparison of the independent and combined effects of sub-chronic therapy with metformin and a stable GLP-1 receptor agonist on cognitive function, hippocampal synaptic plasticity and metabolic control in high-fat fed mice. Neuropharmacology 2014;86(Supplement C):22-30.

56. Li X, Wei J, Matsumura S, Guo Y, Yuan H. Abstract 4033: Epigenetic alterations in the multifaceted inhibitory effects of metformin on castration resistant prostate cancer. Cancer Res 2014;74(19 Supplement):4033.

57. White-Al Habeeb NMA, Garcia J, Fleshner N, Bapat, B. Metformin elicits antitumor effects and downregulates the histone methyltransferase multiple myeloma SET domain (MMSET) in prostate cancer cells. The Prostate 2016;76(16):1507-1518.

58. Tanaka Y, Yano H, Ogasawara S, et al. Mild glucose starvation induces KDM2A-mediated H3K36me2 demethylation through AMPK to reduce rRNA transcription and cell proliferation. Mol Cell Biol 2015;35(24):4170-4184.

59. Bungard D, Fuerth BJ, Zeng P-Y, et al. Signaling kinase AMPK activates stress-promoted transcription via histone H2B phosphorylation. Science 2010;329(5996):1201-1205.

60. Bertoldo MJ, Faure M, Dupont J, Froment P. Impact of metformin on reproductive tissues: an overview from gametogenesis to gestation. Ann Transl Med 2014;2(6):55.

61. Xu Q, Yang C, Du Y, et al. AMPK regulates histone H2B O-GlcNAcylation. Nucleic Acids Res 2014;42(9):5594-5604.

62. Du Y, Zheng H, Wang J, et al. Metformin inhibits histone H2B monoubiquitination and downstream gene transcription in human breast cancer cells. Oncology Lett 2014;8(2):809-812.

63. Cao J, Yan Q. Histone ubiquitination and deubiquitination in transcription, DNA damage response, and cancer. Front Oncol 2012;2:26.

64. Zhong $\mathrm{T}$, Men $\mathrm{Y}, \mathrm{Lu} \mathrm{L}$, et al. Metformin alters DNA methylation genome-wide via the H19/SAHH axis. Oncogene 2017;36(17):2345-2354.

65. Ishikawa $\mathrm{K}$, Tsunekawa $\mathrm{S}$, Ikeniwa $\mathrm{M}$, et al. Long-term pancreatic beta cell exposure to high levels of glucose but not palmitate induces DNA methylation within the insulin gene promoter and represses transcriptional activity. PLoS One 2015;10(2):e0115350.

66. García-Calzón S, Perfilyev A, Männistö V, et al. Diabetes medication associates with DNA methylation of metformin transporter genes in the human liver. Clin Epigenetics 2017;9(1):102.

67. Zhao S, Wu J, Zheng F, et al. $\beta$-elemene inhibited expression of DNA methyltransferase 1 through activation of ERK1/2 and AMPK $\alpha$ signalling pathways in human lung cancer cells: the role of Sp1. J Cell Mol Med 2015;19(3):630-641. 
68. Cuyas E, Fernandez-Arroyo S, Verdura S, et al. Metformin regulates global DNA methylation via mitochondrial one-carbon metabolism. Oncogene 2017. doi:10.1038/onc.2017.367

69. Yan L, Zhou J, Gao Y, et al. Regulation of tumor cell migration and invasion by the H19/let-7 axis is antagonized by metformin-induced DNA methylation. Oncogene 2015;34(23):3076-3084.

70. Noren Hooten N, Martin-Montalvo A, Dluzen DF, et al. Metformin-mediated increase in DICER1 regulates microRNA expression and cellular senescence. Aging Cell 2016;15(3):572-581.

71. Blandino G, Valerio M, Cioce M, et al. Metformin elicits anticancer effects through the sequential modulation of DICER and c-MYC. Nat Commun 2012;3:865.

72. Miyoshi H, Kato K, Iwama H, et al. Effect of the anti-diabetic drug metformin in hepatocellular carcinoma in vitro and in vivo. Int J Oncol 2013;45(1):322-332.

73. Bao B, Wang Z, Ali S, et al. Metformin inhibits cell proliferation, migration and invasion by attenuating CSC function mediated by deregulating miRNAs in pancreatic cancer cells. Cancer Prev Res 2012;5(3):355-364.

74. Misso G, Di Martino MT, De Rosa G, et al. Mir-34: A new weapon against cancer? Mol Ther Nucleic Acids 2014;3:e194.

75. Oliveras Ferraros C, Cufí S, Vazquez Martin A, et al. Micro(mi)RNA expression profile of breast cancer epithelial cells treated with the anti-diabetic drug metformin: induction of the tumor suppressor miRNA let-7a and suppression of the TGF $\beta$-induced oncomiR miRNA-181a. Cell Cycle 2011;10(7):1144-1151.

76. Wang Y, Dai W, Chu X, Yang B, Zhao M, Sun Y. Metformin inhibits lung cancer cells proliferation through repressing microRNA-222. Biotechnol Lett 2013;35(12):2013-2019.

77. Tanaka R, Tomosugi M, Horinaka M, Sowa Y, Sakai, T. Metformin causes G1-phase arrest via down-regulation of miR-221 and enhances TRAIL sensitivity through DR5 up-regulation in pancreatic cancer cells. PLoS One 2015;10(5):e0125779.

78. Santovito D, De Nardis V, Marcantonio P, et al. Plasma exosome microRNA profiling unravels a new potential modulator of adiponectin pathway in diabetes: effect of glycemic control. J Clin Endocrinol Metab 2014;99(9):e1681-e1685.

79. Frost RJ, Olson EN. Control of glucose homeostasis and insulin sensitivity by the let-7 family of microRNAs. Proc Natl Acad Sci USA 2011;108(52):21075-21080.

80. Brennan E, Wang B, McClelland A, et al. Protective effect of let-7 miRNA family in regulating inflammation in diabetes-associated atherosclerosis. Diabetes 2017;66(8):2266-2277.

This article is protected by copyright. All rights reserved. 
81. Coleman CB, Lightell DJ, Moss SC, Bates M, Parrino PE, Woods TC. Elevation of miR-221 and 222 in the internal mammary arteries of diabetic subjects and normalization with metformin. Mol Cell Endocrinol 2013;374:125-129.

82. Arunachalam G, Lakshmanan AP, Samuel SM, Triggle CR, Ding H. Molecular interplay between microRNA-34a and sirtuin1 in hyperglycemia-mediated impaired angiogenesis in endothelial cells: effects of metformin. J Pharmacol Exp Ther 2016;356(2):314-233.

83. Katsura A, Morishita A, Iwama H, et al. MicroRNA profiles following metformin treatment in a mouse model of non-alcoholic steatohepatitis. Int J Mol Med 2015;35(4):877-884.

84. Tsai WC, Hsu SD, Hsu CS, et al. MicroRNA-122 plays a critical role in liver homeostasis and hepatocarcinogenesis. J Clin Invest 2012;122(8):2884-2897.

85. Pan C, Chen H, Wang L, et al. Down-regulation of miR-127 facilitates hepatocyte proliferation during rat liver regeneration. PLoS One 2012;7(6):e39151.

86. Meng X, Guo J, Fang W, et al. Liver microRNA-291b-3p promotes hepatic lipogenesis through negative regulation of Adenosine 5'-Monophosphate (AMP)-activated protein kinase $\alpha 1$. J Biol Chem 2016;291(20):10625-10634.

87. Ortega FJ, Mercader JM, Moreno-Navarrete JM, et al. Profiling of circulating microRNAs reveals common microRNAs linked to type 2 diabetes that change with insulin sensitization. Diabetes Care 2014;37(5):1375-1383.

88. He L, Wondisford FE. Metformin action: concentrations matter. Cell Metab 2015;21(2):159-162.

89. Cabello P, Pineda B, Tormo E, Lluch A, Eroles, P. The antitumor effect of metformin is mediated by miR-26a in breast cancer. Int J Mol Sci 2016;17(8):e1298

90. Wahdan-Alaswad RS, Cochrane DR, Spoelstra NS, et al. Metformin-induced killing of triple negative breast cancer cells is mediated by reduction in fatty acid synthase via miRNA-193b. Horm Cancer 2014;5(6):374-389.

91. Jiang X, Ma N, Wang D, et al. Metformin inhibits tumor growth by regulating multiple miRNAs in human cholangiocarcinoma. Oncotarget 2015;6(5):3178-3194.

92. Sun Y, Tao C, Huang X, et al. Metformin induces apoptosis of human hepatocellular carcinoma HepG2 cells by activating an AMPK/p53/miR-23a/FOXA1 pathway. Onco Targets Ther 2016;9:2845-2853.

93. Kato K, Gong J, Iwama $\mathrm{H}$, et al. The antidiabetic drug metformin inhibits gastric cancer cell proliferation in vitro and in vivo. Mol Cancer Ther 2012;11(3):549-560.

This article is protected by copyright. All rights reserved. 
94. Cifarelli V, Lashinger LM, Devlin KL, et al. Metformin and rapamycin reduce pancreatic cancer growth in obese prediabetic mice by distinct microRNA-regulated mechanisms. Diabetes 2015;64(5):1632-1642.

95. Li W, Yuan Y, Huang L, Qiao M, Zhang Y. Metformin alters the expression profiles of microRNAs in human pancreatic cancer cells. Diabetes Res Clin Pract 2012;96(2):187-195.

96. Kato K, Iwama H, Yamashita T, et al. The anti-diabetic drug metformin inhibits pancreatic cancer cell proliferation in vitro and in vivo: study of the microRNAs associated with the antitumor effect of metformin. Oncol Rep 2016;35(3):1582-1592.

97. Avci CB, Harman E, Dodurga Y, Susluer SY, Gunduz C. Therapeutic potential of an anti-diabetic drug, metformin: alteration of miRNA expression in prostate cancer cells. Asian Pac J Cancer Prev 2013;14(2):765-768.

98. Zhang J, Shen C, Wang L, et al. Metformin inhibits epithelial-mesenchymal transition in prostate cancer cells: involvement of the tumor suppressor miR30a and its target gene SOX4. Biochem Biophys Res Commun 2014;452(3):746-752.

99. Yang F-Q, Wang J-J, Yan J-S, et al. Metformin inhibits cell growth by upregulating microRNA26a in renal cancer cells. Int J Clin Exp Med 2014;7(10):3289-3296. 
Table 1: Effect of metformin on miRNAs in cancer cells

\begin{tabular}{|c|c|c|c|c|}
\hline Cell/tissue source & $\begin{array}{l}\text { Metformin } \\
\text { dose }\end{array}$ & miRNAs altered & Observed effects & Reference \\
\hline $\begin{array}{l}\text { Breast cancer cell lines } \\
\text { MCF-7, BT-474 and } \\
\text { SUM-159 }\end{array}$ & $500 \mu \mathrm{M}$ & $\begin{array}{l}\text { MiR-33a } \\
\text { upregulated }\end{array}$ & $\begin{array}{l}\text { MiR-33a downregulated c-Myc and } \\
\text { IRS-2 }\end{array}$ & $\begin{array}{l}\text { Blandino, et } \\
\text { al. }^{71}\end{array}$ \\
\hline $\begin{array}{l}\text { Breast cancer cell line } \\
\text { MDA-MB- } 231\end{array}$ & $10 \mathrm{mM}$ & $\begin{array}{l}\text { MiR-26a } \\
\text { upregulated }\end{array}$ & $\begin{array}{l}\text { MiR-26a downregulated PTEN, } \\
\text { decreased viability }\end{array}$ & $\begin{array}{l}\text { Cabello, et } \\
\text { al. }^{89}\end{array}$ \\
\hline $\begin{array}{l}\text { Breast cancer cell line } \\
\text { MCF-7 }\end{array}$ & $1 \mathrm{mM}$ & $\begin{array}{l}\text { Let-7a, miR-32, } \\
\text { miR-96 } \\
\text { upregulated } \\
\text { MiR-183 } \\
\text { downregulated }\end{array}$ & $\begin{array}{l}\text { Metformin inhibited formation of } \\
\text { mammospheres }\end{array}$ & $\begin{array}{l}\text { Oliveras } \\
\text { Ferraros, et } \\
\text { al. }^{75}\end{array}$ \\
\hline $\begin{array}{l}\text { Breast cancer cell line } \\
\text { MCF-7 }\end{array}$ & From $1 \mathrm{mM}$ & $\begin{array}{l}\text { MiR-34a } \\
\text { upregulated }\end{array}$ & $\begin{array}{l}\text { MiR-34a downregulated SIRT1 } \\
\text { Metformin increased susceptibility } \\
\text { to oxidative stress }\end{array}$ & Do, et al. ${ }^{51}$ \\
\hline $\begin{array}{l}\text { Breast cancer cells } \\
\text { lines MCF7, MDA- } \\
\text { MB, BT-549, HCC70 }\end{array}$ & $10 \mathrm{mM}$ & $\begin{array}{l}\text { MiR-193a and } \\
\text { miR-193b } \\
\text { upregulated }\end{array}$ & $\begin{array}{l}\text { MiR-193b downregulated fatty acid } \\
\text { synthase (FASN) protein and } \\
\text { induced apoptosis in BT- } 549 \text { cancer } \\
\text { cells but not non-cancerous } \\
\text { MCF10A cells }\end{array}$ & $\begin{array}{l}\text { Wahdan- } \\
\text { Alaswad, et } \\
\text { al. } .^{90}\end{array}$ \\
\hline $\begin{array}{l}\text { Breast cancer cell line } \\
\text { MCF7, endometrial } \\
\text { cancer cell line ARK2 }\end{array}$ & $2 \mathrm{mM}$ & Let-7 upregulated & $\begin{array}{l}\text { Let-7 and AICAR downregulated } \\
\text { H19 }\end{array}$ & Zhong, et al. ${ }^{64}$ \\
\hline $\begin{array}{l}\text { Cholangiocarcinoma } \\
\text { cell lines HCCC-9810, } \\
\text { RBE, SSP25 and } \\
\text { Hucct1 }\end{array}$ & $20-40 \mathrm{mM}$ & $\begin{array}{l}\text { MiR-124, miR- } \\
182, \text { miR-27b and } \\
\text { let- } 7 \mathrm{~b} \text { upregulated } \\
\text { MiR-221 and miR- } \\
\text { 181a } \\
\text { downregulated }\end{array}$ & $\begin{array}{l}\text { MiR-124 downregulated CDK2, } \\
\text { CDK4, CyclinD1 and CyclinE1 } \\
\text { MiR-182 and miR-27b } \\
\text { downregulated CDK2 and CyclinD1 } \\
\text { Let-7b downregulated CyclinD1 } \\
\text { MiR-124, miR-182, miR-27b and } \\
\text { let-7b decreased proliferation } \\
\text { Mir-221 and miR-181a upregulated } \\
\text { p27 and increased proliferation }\end{array}$ & Jiang, et al. ${ }^{91}$ \\
\hline $\begin{array}{l}\text { Hepatocellular } \\
\text { carcinoma cell line } \\
\text { Huh7 }\end{array}$ & $10 \mathrm{mM}$ & $\begin{array}{l}33 \text { upregulated } \\
\text { including let- } 7 \mathrm{a} \text {, } \\
\text { let- } 7 \mathrm{~b}, \text { let-7e, miR- } \\
\text { 34a, miR-26a, } \\
\text { miR-181a. } \\
18 \text { downregulated } \\
\end{array}$ & $\begin{array}{l}\text { Metformin decreased proliferation, } \\
\text { downregulated angiogenin, cyclin } \\
\text { D1, Cdk4 and cyclin E, }\end{array}$ & $\begin{array}{l}\text { Miyoshi, et } \\
\text { al. }^{72}\end{array}$ \\
\hline $\begin{array}{l}\text { Hepatocellular } \\
\text { carcinoma cell line } \\
\text { HepG2 }\end{array}$ & $2.5 \mu \mathrm{M}$ & $\begin{array}{l}\text { MiR-23a } \\
\text { upregulated }\end{array}$ & $\begin{array}{l}\text { MiR-23a downregulated FOXA1, } \\
\text { induced apoptosis }\end{array}$ & Sun, et al. ${ }^{92}$ \\
\hline $\begin{array}{l}\text { Gastric cancer cell line } \\
\text { MKN74 }\end{array}$ & $10 \mathrm{mM}$ & $\begin{array}{l}30 \text { miRNAs } \\
\text { upregulated, } \\
\text { including let-7 } \\
\text { family. } \\
21 \text { downregulated }\end{array}$ & $\begin{array}{l}\text { Metformin decreased proliferation, } \\
\text { downregulated cyclinD1 }\end{array}$ & Kato, et al. ${ }^{93}$ \\
\hline $\begin{array}{l}\text { Lung cancer cell lines } \\
\text { A549 and NCI-H358 }\end{array}$ & $10 \mathrm{mM}$ & $\begin{array}{l}\text { MiR-222 } \\
\text { downregulated }\end{array}$ & $\begin{array}{l}\text { Metformin upregulated p27, p57 and } \\
\text { PTEN and decreased proliferation }\end{array}$ & Wang, et al. ${ }^{76}$ \\
\hline $\begin{array}{l}\text { Pancreatic cancer cell } \\
\text { lines AsPC-1, AsPC- } \\
\text { 1-GTR, MiaPaCa-2, } \\
\text { and MiaPaCa-2-GTR }\end{array}$ & $20 \mathrm{mM}$ & $\begin{array}{l}\text { Let-7a, let-7b, } \\
\text { miR-26a, miR-101, } \\
\text { miR-200b, and } \\
\text { miR-200c } \\
\text { upregulated }\end{array}$ & $\begin{array}{l}\text { MiR-26a downregulated EZH2, } \\
\text { Oct } 4 \text {, Notch-1, and EpCAM } \\
\text { MiR-26a and let-7b decreased } \\
\text { growth of pancreatospheres }\end{array}$ & Bao, et al. ${ }^{73}$ \\
\hline $\begin{array}{l}\text { Pancreatic cancer cell } \\
\text { line Panc } 02\end{array}$ & $0.5 \mathrm{mM}$ & $\begin{array}{l}\text { MiR-34a } \\
\text { upregulated }\end{array}$ & $\begin{array}{l}\text { MiR-34a downregulated Notch. } \\
\text { Metformin decreased tumour sphere } \\
\text { formation }\end{array}$ & $\begin{array}{l}\text { Cifarelli, et } \\
\text { al. }^{94}\end{array}$ \\
\hline $\begin{array}{l}\text { Pancreatic cancer cell } \\
\text { lines Panc1 and } \\
\text { Sw1990 }\end{array}$ & $5 \mathrm{mM}$ & $\begin{array}{l}\text { MiR-26a, miR-192, } \\
\text { and let-7c } \\
\text { upregulated }\end{array}$ & $\begin{array}{l}\text { MiR-26a downregulated HMGA1, } \\
\text { reduced cell proliferation and } \\
\text { migration, and induced apoptosis }\end{array}$ & $\mathrm{Li}$, et al. ${ }^{95}$ \\
\hline $\begin{array}{l}\text { Pancreatic cancer cell } \\
\text { line Panc } 1\end{array}$ & $10 \mathrm{mM}$ & $\begin{array}{l}78 \text { upregulated } \\
\text { including let-7 } \\
\text { family and miR- } \\
150 \\
51 \text { downregulated }\end{array}$ & $\begin{array}{l}\text { Metformin downregulated cyclinD1 } \\
\text { and Cdk } 4 \text { and decreased } \\
\text { proliferation }\end{array}$ & Kato, et al. ${ }^{96}$ \\
\hline
\end{tabular}




\begin{tabular}{|c|c|c|c|c|}
\hline & & including miR-7 & & \\
\hline $\begin{array}{l}\text { Pancreatic cancer cell } \\
\text { line Panc1 }\end{array}$ & $20 \mathrm{mM}$ & $\begin{array}{l}\text { MiR-221 } \\
\text { downregulated }\end{array}$ & $\begin{array}{l}\text { MiR-221 downregulated p27 and } \\
\text { decreased G1-phase arrest }\end{array}$ & Tanaka, et al. $^{77}$ \\
\hline $\begin{array}{l}\text { Prostate cancer cell } \\
\text { line PC-3 }\end{array}$ & $1-5 \mathrm{mM}$ & $\begin{array}{l}10 \text { upregulated } \\
12 \text { downregulated } \\
\text { including miR- } \\
181 \mathrm{a}\end{array}$ & Metformin decreased proliferation & Avci, et al. ${ }^{97}$ \\
\hline $\begin{array}{l}\text { Prostate cancer cell } \\
\text { line Vcap }\end{array}$ & $5 \mathrm{mM}$ & $\begin{array}{l}\text { MiR-30a, miR-143 } \\
\text { and miR-196b } \\
\text { upregulated }\end{array}$ & $\begin{array}{l}\text { MiR-30a downregulated SOX4, } \\
\text { decreased proliferation, migration } \\
\text { and invasion of cancer cells }\end{array}$ & Zhang, et al. ${ }^{98}$ \\
\hline $\begin{array}{l}\text { Renal cancer cell line } \\
786-\mathrm{O}\end{array}$ & $10 \mathrm{mM}$ & $\begin{array}{l}\text { MiR-26 } \\
\text { upregulated }\end{array}$ & $\begin{array}{l}\text { MiR-26a downregulated Blc-2 and } \\
\text { CyclinD1, decreased proliferation }\end{array}$ & Yang, et al. ${ }^{99}$ \\
\hline
\end{tabular}




\section{Legends to figure}

Figure 1: Postulated mechanisms by which metformin may modify histones via AMPK activation.

Metformin phosphorylates (P) and activates AMPK, which subsequently has been found to activate gene expression through the phosphorylation and inactivation of HDACs and activation of HAT1, leading to increased acetylation $(\mathrm{Ac})$ of histone $(\mathrm{H})$ tails. AMPK may also increase gene expression through phosphorylation of histone H2B. Conversely, AMPK may also suppress gene transcription via increasing cellular NAD+ levels and thus increasing SIRT1 deacetylation activity and via phosphorylation and inactivation of HATs p300 and CBP. 
